\title{
New Hemiketal Steroid from the Soft Coral Cladiella sp.
}

Guang-Wen Zhang, Xiang-Quan Ma, Hiroshi Kurihara, Xin-Sheng Yao, Jing-Yu Su, and Long-Mei Zeng*

TABLE OF CONTENTS

Page

${ }^{1} \mathrm{H}$ NMR of Compound 1 -

${ }^{13} \mathrm{C}$ NMR of Compound 1 -

HSQC of Compound 1 - 3

HMBC of Compound 1 -

TOCSY of Compound 1 -

${ }^{1} \mathrm{H}-{ }^{1} \mathrm{H} \mathrm{COSY}$ of Compound 1 -

${ }^{1} \mathrm{H}$ NMR of Compound 1a -

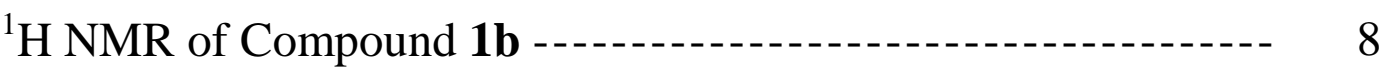




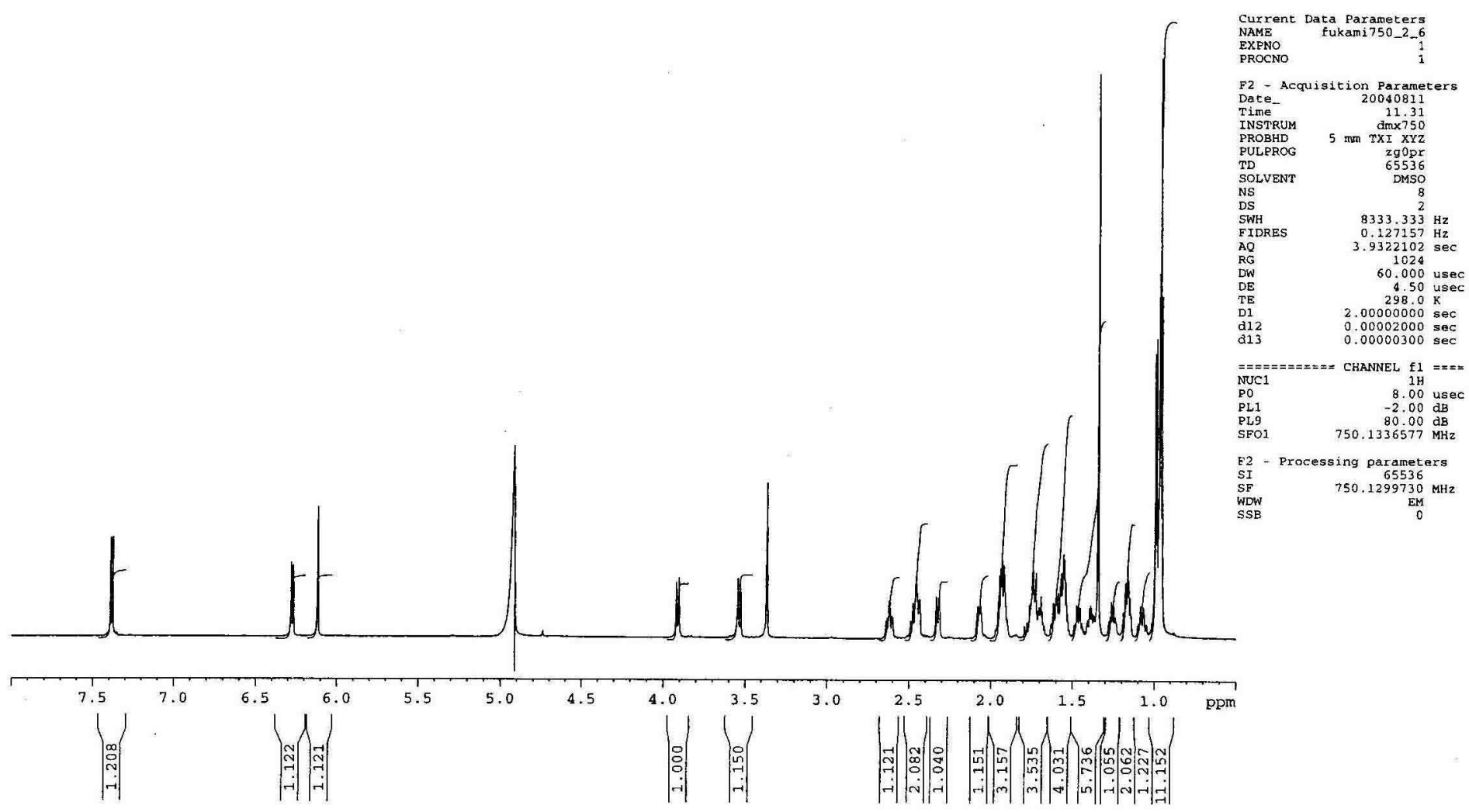

C NMR of compound 1

fukami500_25.1000.1:BBO $\mathrm{ZE}-25 / \mathrm{CD} 30 \mathrm{D} / 298 \mathrm{~K}$ $13 \mathrm{C}(\mathrm{zgpg} 30)$
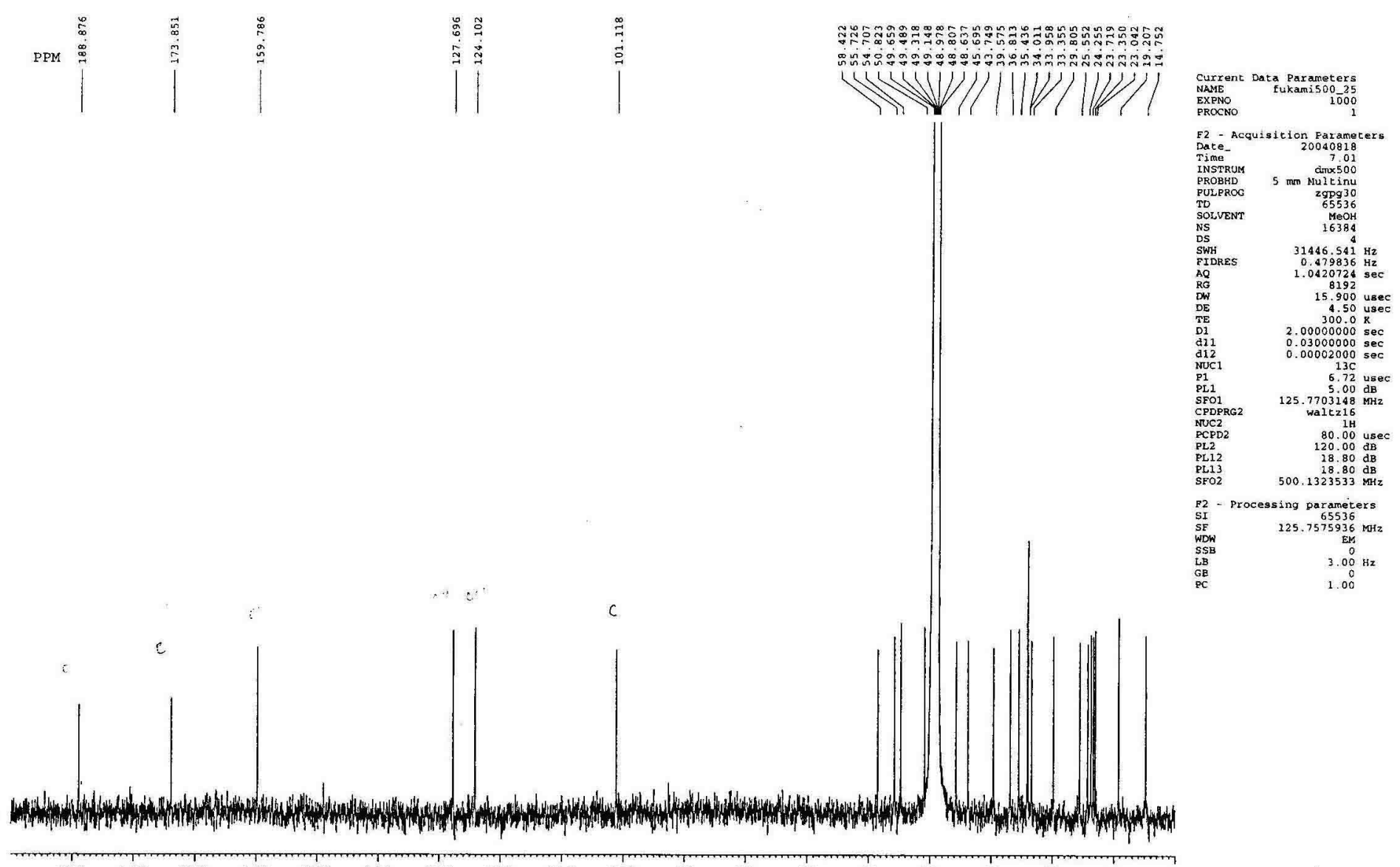

$190 \quad 180$

$90 \quad 80$
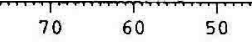

$40 \quad 30$ p ppm 

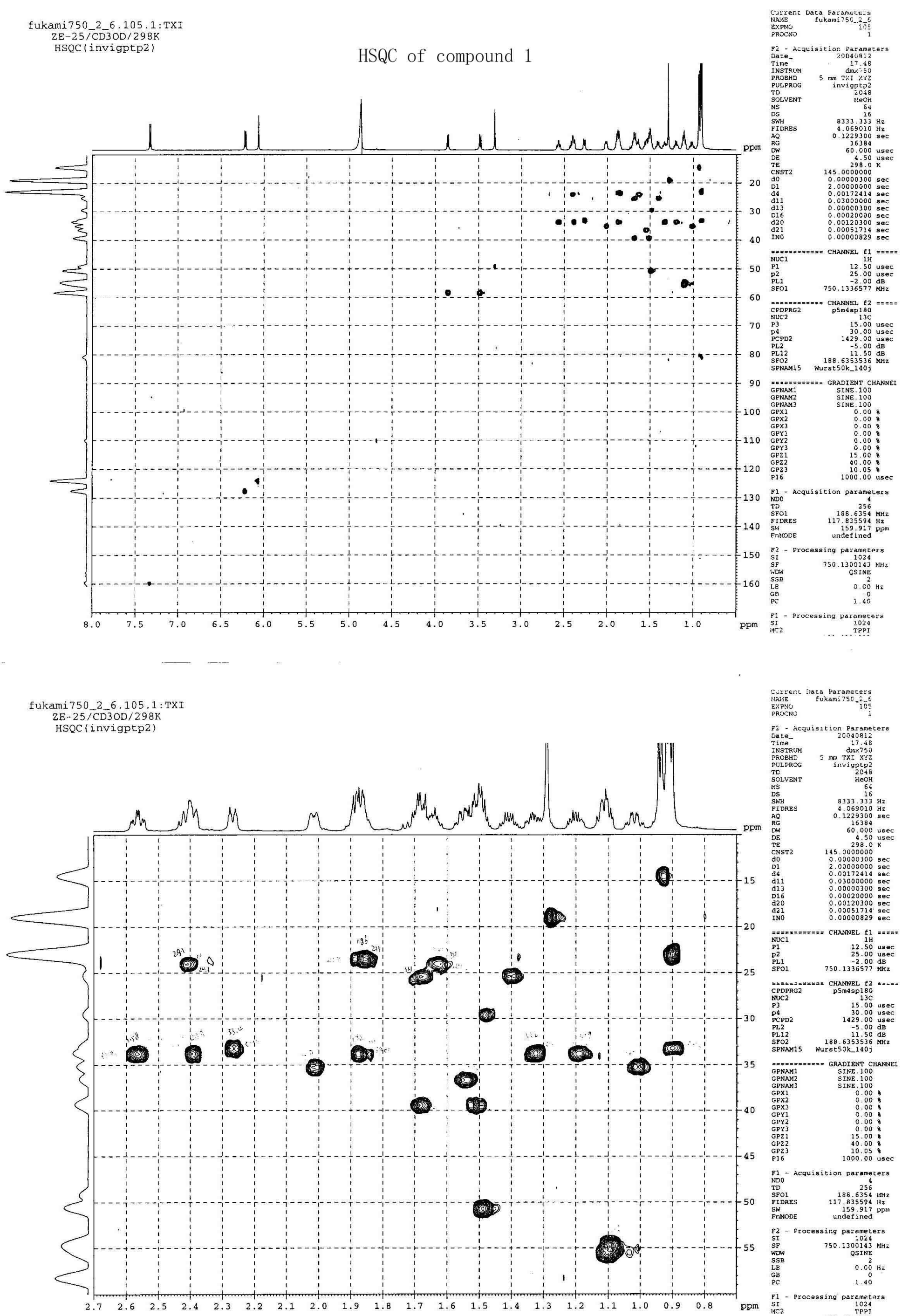


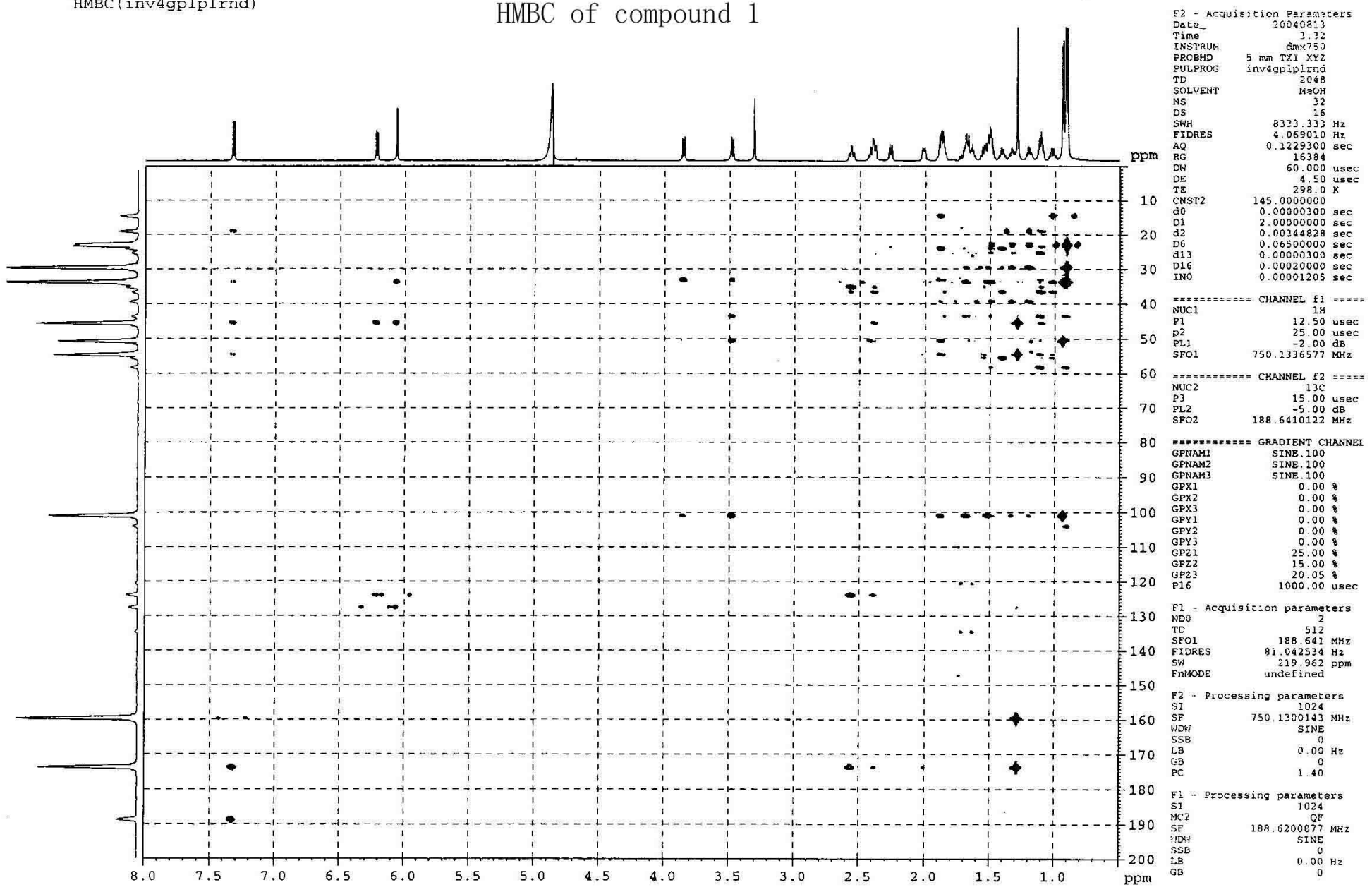

fukami750_2 6.106.1:TXI

$\mathrm{ZE}-25 / \mathrm{CD} 30 \mathrm{D} / 298 \mathrm{~K}$

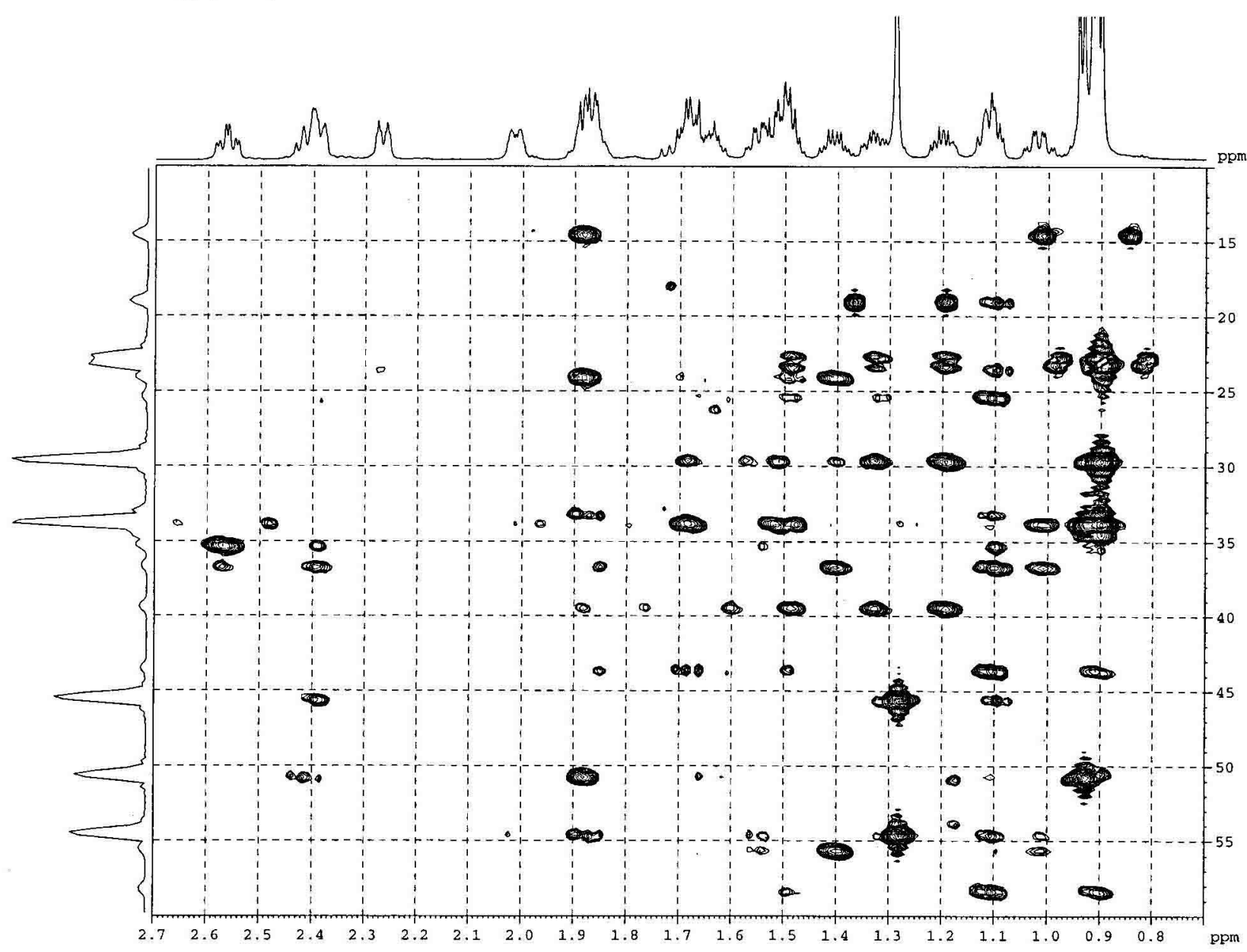

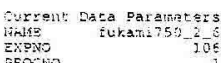

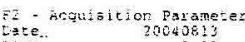

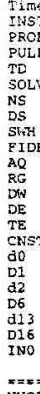

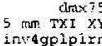

OLWEN

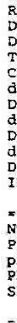

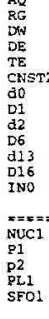

8333.3330

$8333.333 \mathrm{~Hz}$
$4.065010 \mathrm{~Hz}$
0.1229300
$52 \mathrm{sec}$

50.000 use
4.50

4.50
298.0
45.0000000

0.00000300
2.00000000
0.0000

0.00344828 sec
0.06500000
0.00000300
0.0606

$0.00020000 \mathrm{sec}$
$0.00001205 \mathrm{sec}$

CHANNEL ${ }_{11}^{11} x=s$

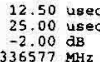

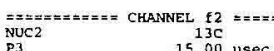

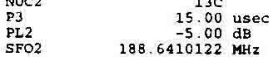

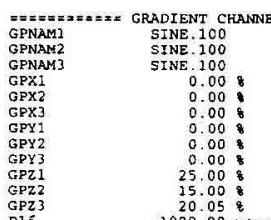

F1- Acquisition parameters

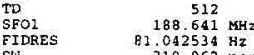

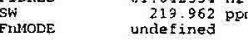

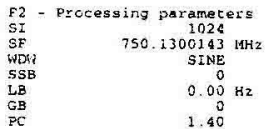

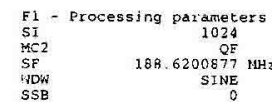



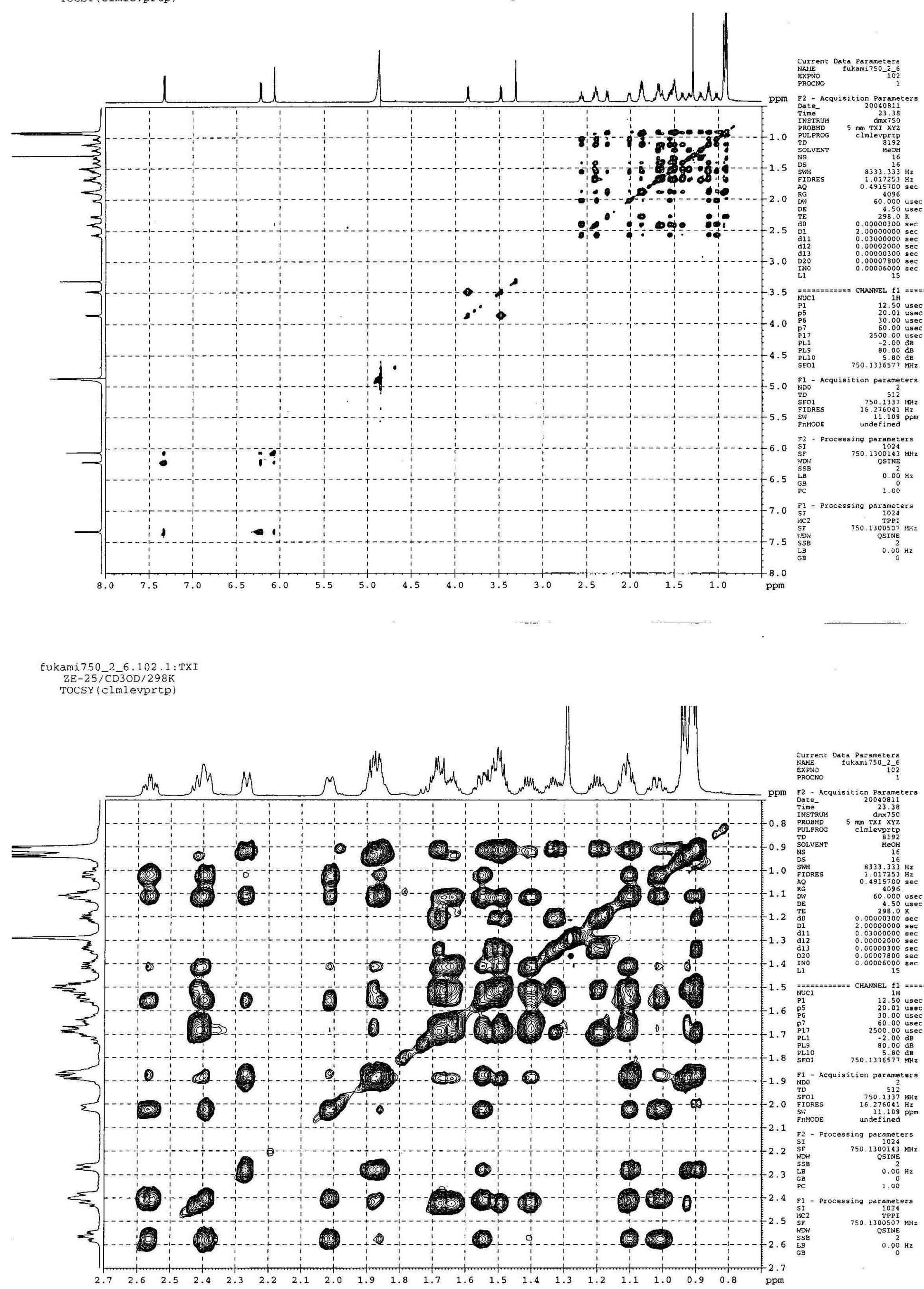


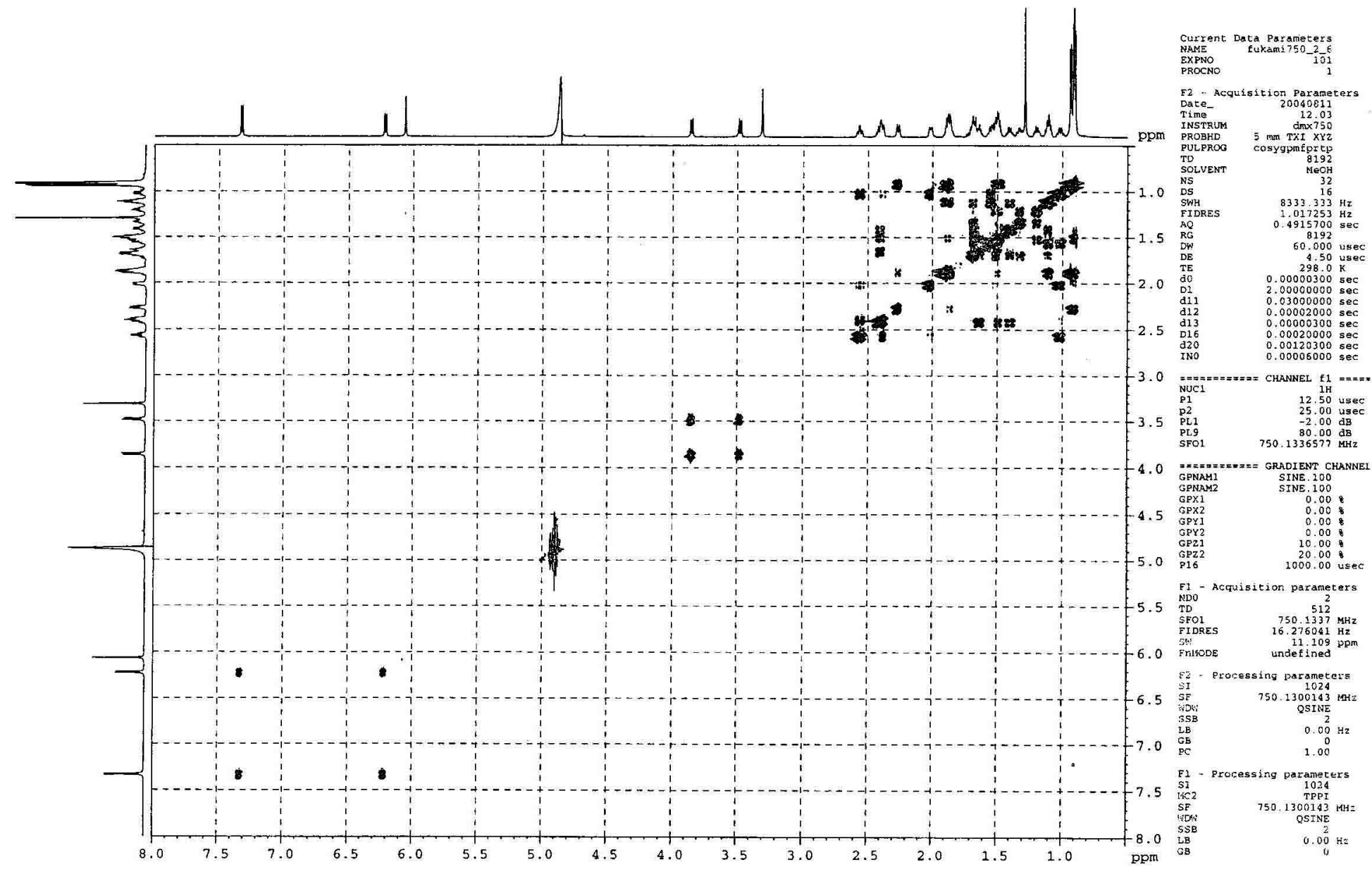

fukami750_2_6.101.1:TXI

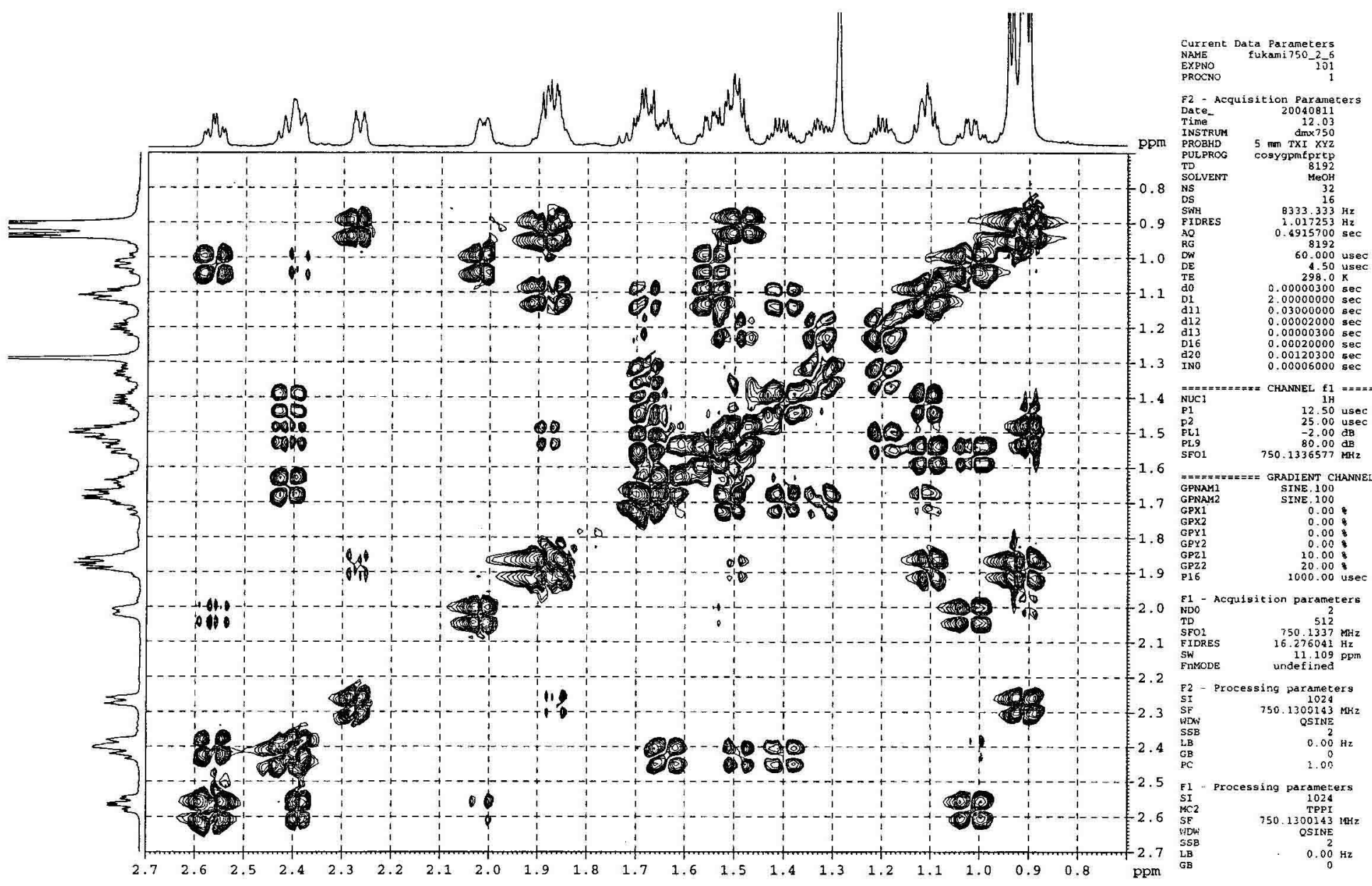




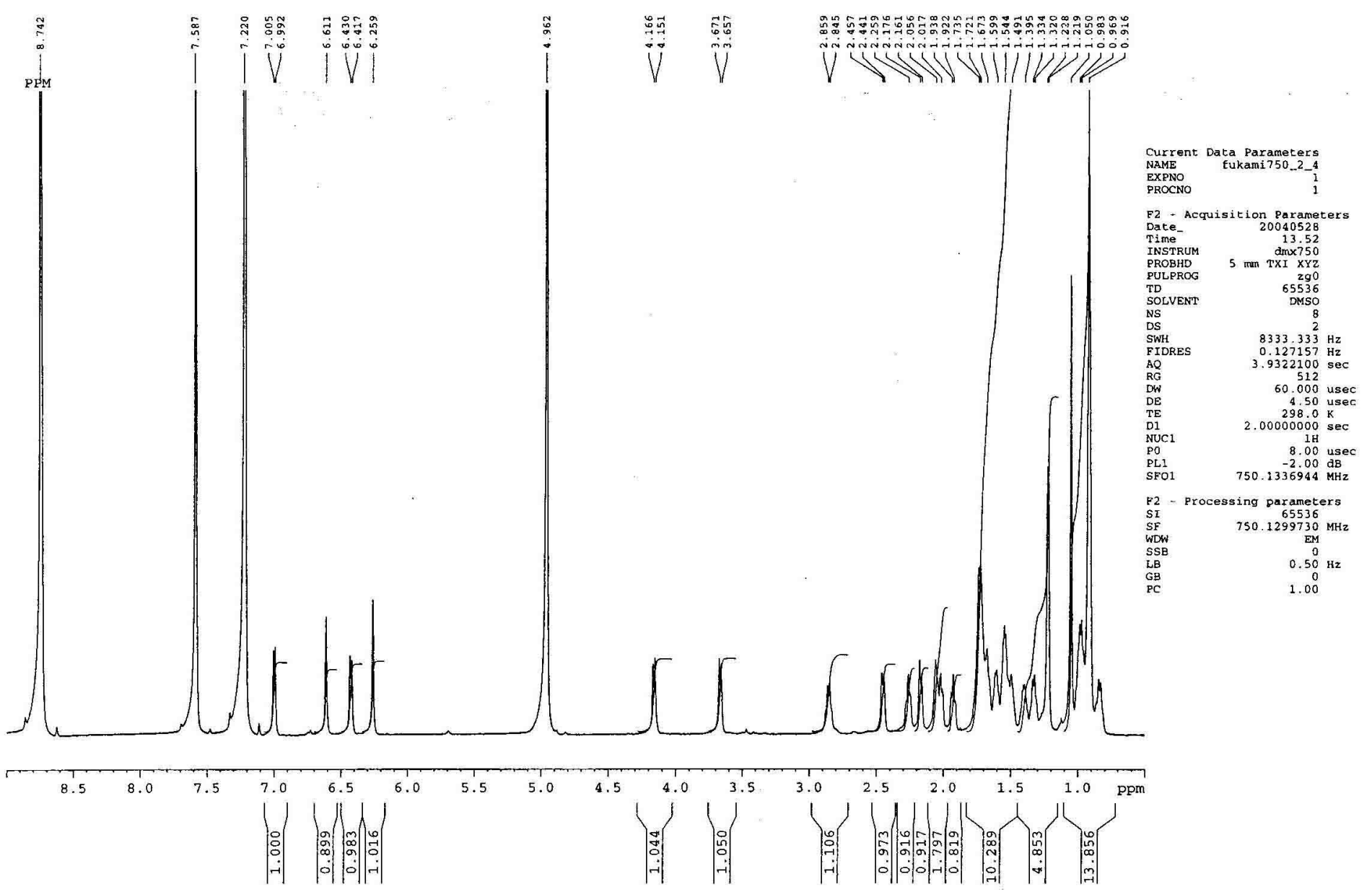

fukami750_2-4.1.1:TXI $\mathrm{E}-25 / \mathrm{Pyr}-\overline{\mathrm{a}} 5 / 298 \mathrm{~K}$ $1 \mathrm{H}(\mathrm{zgO})$

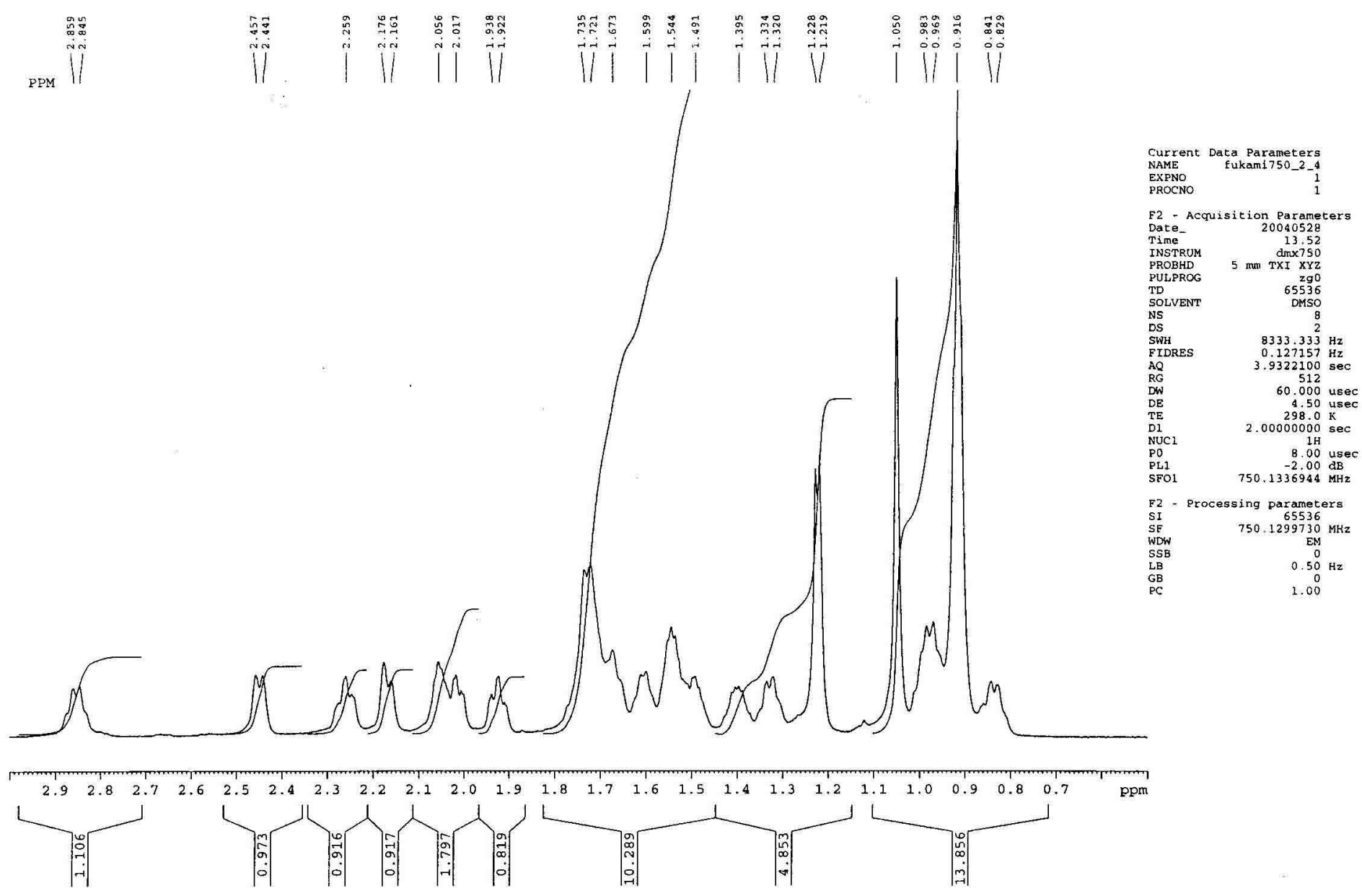

